\section{Identifying skull fractures in young children}

Gravel and colleagues describe the derivation and validation of a clinical rule to identify skull fractures in children with isolated head trauma. ${ }^{1}$ Their study identified young age ( $<2$ months) and parietal or occipital hematoma as predictors of skull fracture on skull x-rays.

However, the article and the accompanying commentary ${ }^{2}$ ignore a safer tool that minimizes unnecessary radiation exposure in children who have suffered a minor head injury: point of care ultrasound (POCUS).

POCUS can be used at the bedside to rapidly identify a skull fracture without the use of radiation. It has been shown to have a sensitivity of $82 \%$ to $100 \%$ and a specificity of $94 \%$ to $97 \%$ for identifying skull fractures in children compared with computerized tomography scans..$^{3-5}$ The technique for POCUS may be learned in as little as one hour of combined didactic and hands-on training. ${ }^{4}$

Not only do skull x-rays carry radiation risk, they may be more difficult to interpret. Chung and colleagues found that skull x-rays had a sensitivity of $76 \%$ and a specificity of $84 \%$ for identifying skull fractures when interpreted by pediatric emergency physicians. ${ }^{6}$

\section{Allan Shefrin MD \\ Terry Varshney MD}

Division of Pediatric Emergency Medicine, Children's Hospital of Eastern Ontario, Ottawa, Ont.

\section{References}

1. Gravel J, Gouin S, Chalut D, et al. Derivation and validation of a clinical decision rule to identify young children with skull fracture following isolated head trauma. CMAJ 2015;187:1202-8.

2. Gill PJ, Klassen T. Managing isolated head trauma in young children. CMAJ 2015;187:1189-90.

3. Riera A, Chen L. Ultrasound evaluation of skull fractures in children: a feasibility study. Pediatr Emerg Care 2012;28:420-5.

4. Rabiner JE, Friedman LM, Khine H, et al. Accuracy of point-of-care ultrasound for diagnosis of skul fractures in children. Pediatrics 2013;131:e1757-64.

5. Parri N, Crosby BJ, Glass C, et al. Ability of emergency ultrasonography to detect pediatric skull fractures: a prospective, observational study. J Emerg Med 2013;44:135-41.

6. Chung S, Schamban N, Wypij D, et al. Skull radiograph interpretation of children younger than two years: How good are pediatric emergency physicians? Ann Emerg Med 2004;43:718-22.

CMAJ 2016. DOI:10.1503/cmaj.1150085

\section{Health benefits of hosting major international events}

The fact that there is an overlap between what is considered health - and hence disease prevention - and injury prevention is often overlooked. ${ }^{1}$ This is unfortunate given the clear contribution of injuries to the global ill-health burden and the potential for injury prevention efforts to contribute substantially to the promotion of health and the reduction of health services needed to treat injuries.

It may surprise some to learn of an unexpected legacy from the Sydney 2000 Olympic Games. ${ }^{2}$ General injury surveillance in public emergency departments during the Olympic Games found an increase in the number of injuries from broken glass, especially at the start of the games. This prompted immediate action - that is, beer and other drinks were no longer available for purchase by the public or allowed to be brought to venues by the public in glass bottles and containers. Following this action, the rate of such injuries was shown to be reduced. Now, for all large sporting events across Australia, glass containers cannot be brought in by the public, and all drinks for purchase are provided in plastic cups.

This is a great example of how simple measures to prevent injury can greatly affect the health of all populations.

\section{Caroline F. Finch PhD MSc}

Robert HT Smith Professor and Principal Research Fellow, National Health and Medical Research Council, Australian Centre for Research into Injury in Sport and its Prevention, Federation University Australia, Victoria, Australia

\section{References}

1. MacAuley D. The health legacy of hosting major sporting events. CMAJ 2015;187:1267.

2. Jorm LR, Thackway SV, Churches TR, et al. Watching the games: public health surveillance for the Sydney 2000 Olympic Games. J Epidemiol Community Health 2003;57:102-8.

CMAJ 2016. DOI:10.1503/cmaj.1150086

\section{NOACs: drug-drug interactions}

We commend Fralick and colleagues for their article on drug interactions with rivaroxaban. ${ }^{1}$ All novel oral anticoagulants
(NOACs) were introduced as at least noninferior (in some cases superior) to warfarin. In addition to high efficacy, NOACs were reported to have a better safety profile with the added advantage of eliminating the requirement for regular coagulation monitoring. ${ }^{2}$

Despite fewer food interactions, physicians still have to consider drug-drug interactions when prescribing NOACs. These pharmacokinetic interactions were divided into three levels of warnings: red alert precludes the use of a given NOAC (contraindicated/discouraged); orange alert prompts adapting the NOAC dose; and yellow alert allows for maintaining the original dose unless two or more yellow interactions are present - in which case, the NOAC dose may need to be adapted (orange) or the drug not prescribed at all (red). For many potential interactions with medications often used for atrial fibrillation or other comorbidities, no detailed information is available. It is prudent to abstain from using NOACs until more data are available. Clinicians prescribing NOACs must be aware of relevant drug-drug interactions as well as of the limited possibilities to assess the level of anticoagulation. Close collaboration with pharmacists and anticoagulation specialists seems crucial. ${ }^{3}$

\section{Bartosz Hudzik MD PhD \\ Andrzej Lekston MD PhD \\ Mariusz Gasior MD PhD}

Third Department of Cardiology, Silesian Centre for Heart Disease, SMDZ in Zabrze, Medical University of Silesia, Zabrze, Poland

\section{References}

1. Fralick M, Juurlink DN, Marras T. Bleeding associated with coadministration of rivaroxaban and clarithromycin. CMAJ 2016. [Epub ahead of print 2016 Jan. 25.]

2. Heidbuchel H, Verhamme P, Alings M, et al. Updated European Heart Rhythm Association Practical Guide on the use of non-vitamin K antagonist anticoagulants in patients with non-valvular atrial fibrillation. Europace 2015;17:1467-507.

3. Altena R, van Roon E, Folkeringa R, et al. Clinical challenges related to novel oral anticoagulants drug-drug interactions and monitoring. Haemato logica 2014;99:e26-7.

CMAJ 2016. DOI:10.1503/cmaj.1150087

\section{Letters to the editor}

Letters have been abbreviated for print. See www.cmaj.ca for full versions and competing interests. 